12

\title{
Повышающе-понижающий преобразователь напряжения для заряда аккумуляторной батареи на борту электрического самолета
}

\author{
() С.И. Мошкунов, В.Ю. Хомич, Е.А. Шершунова \\ Институт электрофизики и электроэнергетики РАН, Санкт-Петербург, Россия \\ ฯ E-mail: eshershunova@ieeras.ru
}

Поступило в Редакцию 2 декабря 2019г.

В окончательной редакции 2 декабря 2019г.

Принято к публикации 27 апреля 2020 г.

\begin{abstract}
Разработан мощный импульсный преобразователь постоянного напряжения для заряда аккумуляторных сборок на борту гибридных и электросамолетов, позволяющий осуществлять полный заряд емкости аккумуляторной батареи в режиме крейсерского полета летательного аппарата. Преобразователь модульной конструкции на $10 \mathrm{~kW}$ может работать как в повышающем, так и в понижающем режиме в диапазоне напряжений $130-300 \mathrm{~V}$ с ограничением по току в $70 \mathrm{~A}$ при выходном напряжении $150 \mathrm{~V}$. КПД созданного преобразователя составляет $\sim 96-99 \%$ в зависимости от мощности, потребляемой в нагрузке. Предложенная модульная конструкция и многофазная схема управления могут быть использованы для построения преобразователей разной мощности с высоким КПД.
\end{abstract}

Ключевые слова: преобразователь напряжения, buck/boost, электрический самолет, аккумуляторная батарея.

DOI: 10.21883/PJTF.2020.15.49743.18139

С разрастанием городов и увеличением количества авиаперевозок все более актуальной становится проблема как уменьшения вредных выбросов в атмосферу, так и снижения шума и вибраций. Ее успешным решением может быть частичный или полный отказ от двигателей внутреннего сгорания и переход к гибридным или полностью электрическим летательным аппаратам - так называемой „зеленой авиации“ $[1,2]$. Источниками на борту таких самолетов могут быть суперконденсаторы, топливные элементы и аккумуляторные батареи [3]. У каждого из этих элементов электропитания есть свои особенности работы. Так, топливные элементы рациональнее всего использовать во время крейсерского полета, поскольку они способны запасать большую энергию и расходовать ее при постоянном потреблении, а аккумуляторные батареи, наоборот, эффективнее применять при наборе высоты, когда тяговая мощность может меняться скачкообразно [4]. Кроме того, аккумуляторные батареи можно подзаряжать во время полета, что позволит выиграть дополнительную энергию для увеличения дальности полета или случая экстренного маневрирования. Эффективная работа всех описанных источников электроэнергии невозможна без применения импульсных преобразователей напряжения. Они нужны как для стабилизации напряжения на шине питания мотора, так и для обеспечения оптимального режима заряда аккумуляторов, когда накладываются жесткие ограничения, в частности ограничения тока заряда.

Важным параметром, характеризующим такие преобразователи, является их удельная мощность (отношение мощности, которую может обеспечить преобразователь, к его массе). Она может быть увеличена за счет применения современной компонентной базы, за счет использования многофазной схемы, которая также будет способствовать уменьшению пульсаций тока [5], а также за счет увеличения рабочего напряжения на борту летательного аппарата [6].

Сегодня выпускаются готовые интегральные схемы повышающе-понижающих преобразователей, однако их низкие рабочие напряжения не позволяют использовать эти решения для построения эффективных мощных силовых установок в составе летательных аппаратов.

Созданный преобразователь напряжения работает в диапазоне 130-300 V и выдает на выходе постоянное напряжение $150 \mathrm{~V}$. Преобразователь имеет модульную структуру, благодаря чему можно варьировать выходную мощность. Модуль состоит из трех плат (рис. 1): платы управления (PWM-board), силовой платы (buck/boost), на которой размещены силовые транзисторы, и платы накопительных конденсаторов. Каждый модуль управляется по сигналу с тактового генератора импульсов (clock-generator), сигналы управления которого для каждого модуля сдвинуты по фазе на четверть периода. Принцип работы преобразователя можно пояснить с помощью рис. $1, a$.

Пара $Q 1-D 1$ ответственна за понижение напряжения (buck-режим), а пара $Q 2-D 2$ - за его повышение (boost-режим). В диапазоне входных напряжений 150-300 V схема работает в режиме понижающего преобразователя, при этом транзистор постоянно закрыт. Для эффективной стабилизации токов и напряжений в диапазоне входных напряжений $V_{i n} 130-158 \mathrm{~V}$ схема работает в смешанном понижающем-повышающем режиме [7]. В указанном диапазоне входных напряжений в этом режиме длительность импульса, подаваемого на $Q 2$, линейно уменьшается с $1.8 \mu$ s до нуля. 

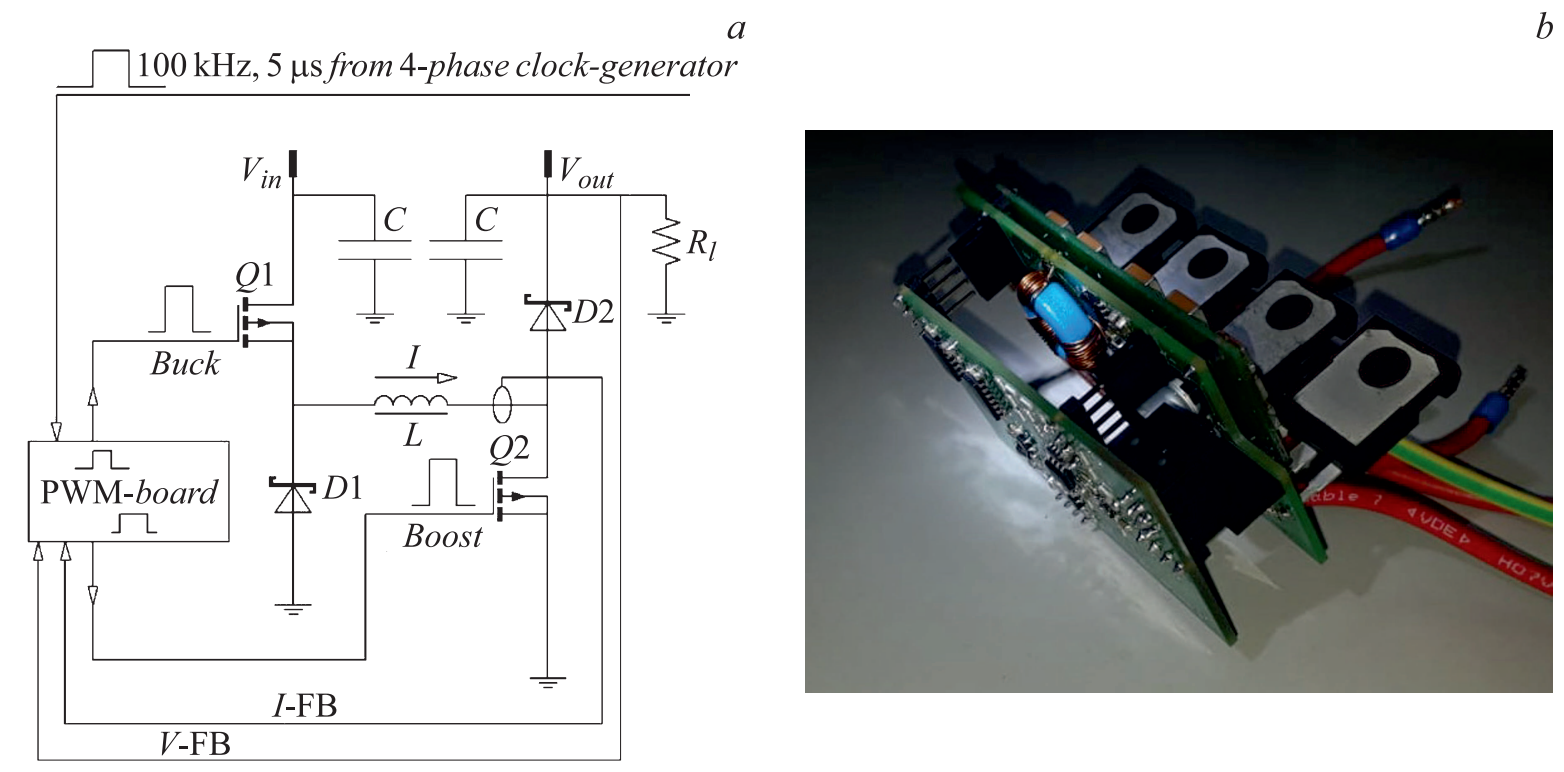

Рис. 1. $a-$ схема одного модуля (принцип работы преобразователя), $b-$ фотография модуля на $2.5 \mathrm{~kW}$.

Плата управления имеет обратную связь по напряжению и току и основана на принципе широтноимпульсной модуляции (pulse width modulation, PWM), что часто используется в преобразователях [8]. При сравнении опорного пилообразного сигнала частотой $100 \mathrm{kHz}$ и уровня напряжения, определяемого напряжением на выходе устройства по обратной связи $(V-\mathrm{FB})$, формируются импульсы той или иной длительности, которая и обеспечивает требуемое напряжение на выходе преобразователя. В преобразователе также предусмотрено ограничение по току. Средний ток через силовой дроссель $L$ измеряется с помощью датчика на основе эффекта Холла ACS730 (фирма Allegro), установленного на силовой плате, и затем через делитель по обратной связи (I-FB) подается на усилитель ошибки, куда также приходит опорный сигнал необходимого уровня тока. Следует отметить, что ток дросселя стабилизируется за счет изменения длительности импульса, подаваемого на $Q 1$ [9]. От ложного срабатывания между периодами импульсов используется RS-триггер.

На силовой плате также выполнены дополнительные гальванически развязанные источники питания $+15 \mathrm{~V}$ для драйверов силовых транзисторов $Q 1$ и Q2 IPW60R017, рассчитанных на рабочее напряжение до $600 \mathrm{~V}$ и ток до $100 \mathrm{~A}$. В качестве диодов используются силовые диоды Шоттки C5D50065D с обратным напряжением $650 \mathrm{~V}$ и током до $50 \mathrm{~A}$. Дроссели выполнены на кольцевом сердечнике с распределенным воздушным зазором из сендаста фирмы Magnetics. Сглаживающие SMD-конденсаторы расположены на отдельной плате. Теплоотвод сделан в виде алюминиевой пластиныоснования, к которой прижата алюминиевая квадратная профильная труба, через которую прокачивается охлаждающая жидкость. Силовые транзисторы и диоды

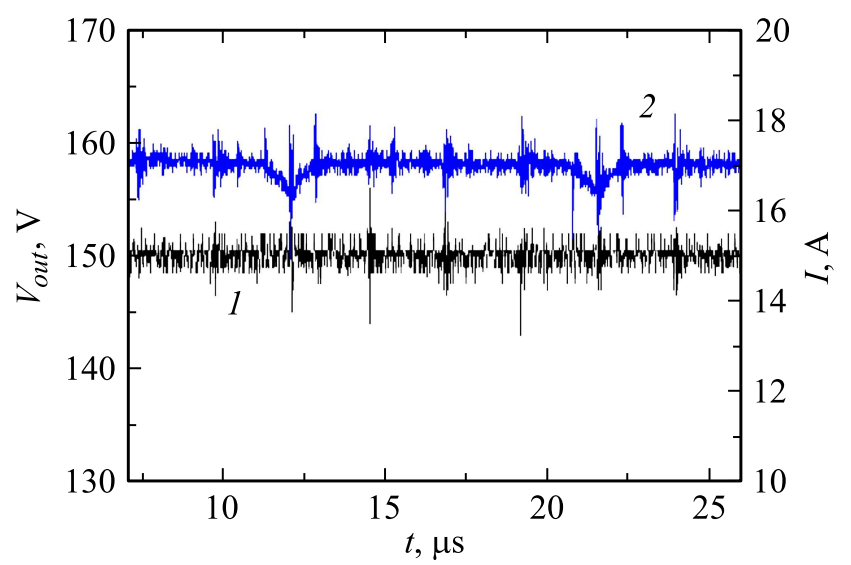

Рис. 2. Осциллограммы выходного напряжения $V_{\text {out }}(1)$ и тока $I$ через дроссель одного из модулей преобразователя (2) при входном напряжении $130 \mathrm{~V}$.

имеют непосредственный тепловой контакт с трубой, а дроссели - с пластиной.

Было проведено тестирование работы четырехфазного преобразователя с четырьмя модулями, соединенными параллельно при работе в повышающем режиме. На рис. 2 представлены типичные осциллограммы тока через дроссель одного из модулей и напряжения на нагрузке. Изменение напряжения на выходе регистрировалось с помощью пробника напряжения с коэффициентом деления $1: 10$, а тока - с помощью высокочувствительного пробника. После этого данные выводились на экран цифрового осциллографа с полосой $200 \mathrm{MHz}$ и записывались в цифровом виде.

Как видно из рис. 2, средний ток в дросселе одного модуля составляет $17 \mathrm{~A}$, при этом на кривой тока 


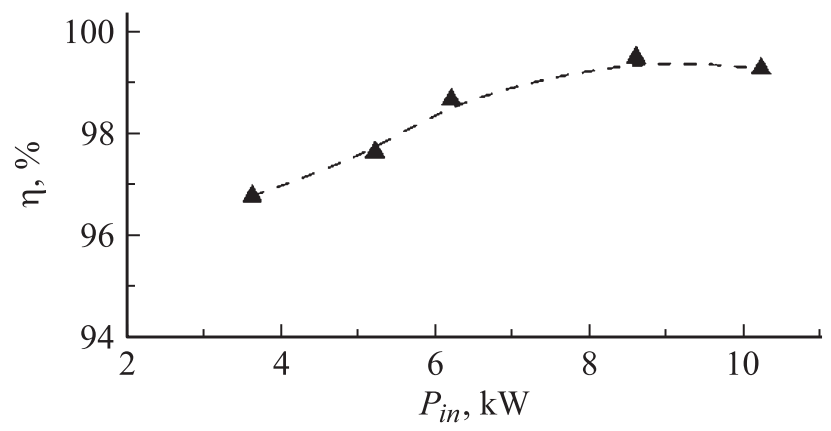

Рис. 3. Зависимость КПД преобразователя $\eta$ от потребляемой мощности $P_{i n}$.

видны всплески, отвечающие наводкам от срабатывания соседних модулей. Согласно данным осциллограммы, пульсации тока составляют $1 \mathrm{~A}$ (от пика до пика). Значение выходного напряжения преобразователя при этом равно $150 \mathrm{~V}$.

При разной нагрузке была проведена оценка КПД созданного преобразователя. Зависимость КПД от потребляемой мощности при работе преобразователя в повышающем режиме показана на рис. 3. Кривая имеет характерный вид: наибольший КПД $(\sim 99 \%)$ обеспечивается при потребляемой мощности $8-10 \mathrm{~kW}$.

Созданный четырехфазный преобразователь достаточно компактный $(45 \times 135 \times 410 \mathrm{~mm})$, а его масса составляет $2.55 \mathrm{~kg}$. Отличительной чертой преобразователя является его многофазный режим работы, который обеспечивает сглаживание входных и выходных токов и напряжений, а также модульность его конструкции. Такой подход позволяет создавать преобразователи напряжения различной мощности с достаточно высоким КПД. Построенные по такому принципу полностью управляемые по току и напряжению преобразователи напряжения могут в перспективе быть успешно использованы на борту электрических и гибридных самолетов для заряда аккумуляторных батарей при полете в крейсерском режиме, когда энергия расходуется из других источников.

\section{Финансирование работы}

Работа выполнена при поддержке программы Президиума РАН № 7 „Новые разработки в перспективных направлениях энергетики, механики и робототехники“.

\section{Конфликт интересов}

Авторы заявляют, что у них нет конфликта интересов.

\section{Список литературы}

[1] Gohardani A.S., Dunn R., Millecam N. // 54th AIAA Aerospace Sciences Meeting. San Diego, California, USA, 2016. AIAA 2016-0865 (1-19). https://doi.org/10.2514/6.2016-0865
[2] Morioka N., Takeuchi M., Oyori H. // IHI Eng. Rev. 2014. V. 47. N 1. P. 33-39.

[3] Khaligh A., Li Z. // IEEE Trans. Veh. Technol. 2010. V. 59. N 6. P. 2806-2814.

[4] Romeo G., Borello F., Correa G., Cestino E. // Int. J. Hydrogen Energy. 2013. V. 38. N 1. P. 469-479.

[5] Варюхин А.Н., Малашин М.В., Мошкунов С.И., Хомич B.Ю., Шериунова E.A. // Тез. докл. Науч.-практ. конф. ученых России и Хорватии. М.: НИТУ „МИСиС“, 2019. C. 192-193.

[6] Kreutzer O., Eckardt B., März M. // 2014 16th IEEE European Conference on Power Electronics and Applications. IEEE, 2014. P. 1-10. DOI: 10.1109/EPE.2014.6910797

[7] Gaboriault M., Notman A. // Nineteenth Annual IEEE Applied Power Electronics Conference and Exposition (APEC'04). IEEE, 2004. V. 3. P. 1411-1415.

[8] Мошкунов С.И., Хомич В.Ю., Шершунова Е.А. // Письма в ЖТФ. 2018. Т. 44. В. 2. С. 104-110.

[9] Dixon L. // Unitrode Power Supply Design Seminar Handbook. Unitrode Corporation, 1990. P. 5.1. 